\title{
IMPACT OF VERY HIGH-FREQUENCY SOUND AND LOW-FREQUENCY ULTRASOUND ON PEOPLE - THE CURRENT STATE OF THE ART
}

\author{
Nofer Institute of Occupational Medicine, Łódź, Poland \\ Department of Physical Hazards
}

MALGORZATA PAWLACZYK-LUSZCZYŃSKA and ADAM DUDAREWICZ

\begin{abstract}
For several decades, low-frequency ultrasound $(<100 \mathrm{kHz})$ has been widely used in industry, medicine, commerce, military service and the home. The objective of the study was to present the current state of the art on the harmful effects of low-frequency airborne ultrasound on people, especially in occupational settings. The scientific literature search was performed using accessible medical and other databases (WOS, BCI, CCC, DRCI, DIIDW, KJD, MEDLINE, RSCI, SCIELO and ZOOREC), and the obtained results were then hand-searched to eliminate non-relevant papers. This review includes papers published in 1948-2018. The potential effects of the low-frequency airborne ultrasound have been classified as auditory and non-auditory effects, including subjective, physiological, and thermal effects. In particular, already in the 1960-1970s, it was demonstrated that ultrasonic exposure, when sufficiently intense, appeared to result in a syndrome involving nausea, headache, vomiting, disturbance of coordination, dizziness, and fatigue, and might cause a temporary or permanent hearing impairment. However, since that time, not too much work has been done. Further studies are needed before any firm conclusions can be drawn about the auditory and non-auditory effects of low-frequency airborne ultrasound. Int J Occup Med Environ Health. 2020;33(4):389-408
\end{abstract}

Key words:

low-frequency airborne ultrasound, high-frequency sound, occupational exposure, impact on humans, auditory effects, non-auditory effects

\section{INTRODUCTION}

The most common definition of ultrasound refers to acoustic waves with frequencies higher than the upper audible limit of human hearing. This limit varies $(10-20 \mathrm{kHz})$ from person to person and is approx. $16-20 \mathrm{kHz}$ in healthy young adults [1]. Ultrasound is not different from "normal" (audible) sound in its physical properties, except that people cannot hear it.

Ultrasound can spread in elastic materials with interactions depending on the frequency. This is manifested by the occurrence of various physical phenomena in the media where ultrasound propagates (e.g., thermal effects, cavitation), which entails a variety of ultrasound applications in industry, medicine and everyday life [2-4]. Ultrasound devices operate with frequencies of $16 \mathrm{kHz}-$ $1 \mathrm{GHz}$. Depending on the frequency, there are different methods of its generation and application, as well as different interactions with media and mechanisms of influence on living organisms, leading to various bio-effects $[3,4]$. Such a situation implies a division of ultrasound into low-

Funding: the work was supported by the Ministry of Health in Poland within the National Health Programme for the 2016-2020 (NPZ 2016-2020, project No. 6/4/10/ NPZ/FRPW/2018/312/515A, entitled "Monitoring of the physical, chemical and biological hazards in the workplace. A) Monitoring of exposure to noise in employees of various professional groups," project manager: Małgorzata Pawlaczyk-Łuszczyńska, Ph.D., NIOM professor).

Received: December 20, 2019. Accepted: March 27, 2020.

Corresponding author: Małgorzata Pawlaczyk-Łuszczyńska, Nofer Institute of Occupational Medicine, Department of Physical Hazards, św. Teresy 8, 91-348 Łódź, Poland (e-mail: Malgorzata.Pawlaczyk@imp.lodz.pl). 
frequency ultrasound $(<100 \mathrm{kHz})$ and (very) high-frequency ultrasound $(>100 \mathrm{kHz})[2]$.

This classification reflects the scope of industrial, domestic and medical applications of ultrasound. For example, lowfrequency ultrasound is used in industrial applications, e.g., for plastic and metal welding, cleaning or mixing, while in medical applications for some therapeutic procedures. In turn, high-frequency ultrasound $(>100 \mathrm{kHz})$ can be used in medical diagnostics or acoustic microscopy, industrial flaw detection and non-destructive testing of thickness [2,3].

Recently, a more accurate classification of ultrasound by frequency has been proposed by Duck and Leighton [1]. They suggested that, depending on the health effects, the ultrasound spectrum should be divided into 3 bands, i.e., the lowest $(17.8-500 \mathrm{kHz})$, middle $(500 \mathrm{kHz}-100 \mathrm{MHz})$ and highest band (>100 MHz). In the lowest band, the dominant phenomenon causing biological effects is the acoustic cavitation in fluids and soft tissues, whereas health effects from airborne ultrasound have been reported but are far less studied. In the middle band, the temperature rise in tissues becomes the most important biological effect of exposure. In turn, the highest band covers the frequencies for which the radiation force becomes an increasingly important biophysical mechanism [1].

More and more methods of generating ultrasound with different frequencies and applications of ultrasound appear along with technological development. Human exposure to low-frequency ultrasound ( $\leq 100 \mathrm{kHz}$ ) can be done in 2 ways, first by contact with vibrating objects directly or via a liquid, and second by energy transfer in the air. The biological effects caused by ultrasound depend on the amounts of energy delivered by the ultrasound, and these depend on the amplitude and time of action on the organisms. Low-frequency medical ultrasound applications mostly involve contact exposure, whereas industrial applications may involve both contact and airborne exposures [3].
An air-tissue interface provides a highly reflecting boundary, which may bounce back up to $99 \%$ of incident ultrasound energy. Consequently, airborne exposure has only limited penetration into the human body. When there is a need for a greater ultrasound penetration to provide information (imaging) or generate therapeutic effects in medical applications, a contact exposure technique is used. The air gap between the transducer and the skin is eliminated using a coupling medium with the probe being placed in direct contact with the body. Therefore, the impact of airborne ultrasound on the human body is mainly confined to external body organs such as the ear and the eye [2,5].

In turn, the contact exposure can be either non-invasive (when the exposure is through the intact skin surface) or invasive (where a macroscopic mechanical change is induced directly in the tissues using ultrasonic vibrations from a driven tool, e.g., for cutting tissues in ultrasonic surgery) [3].

Due to a wide range of topics related to ultrasound, this article will focus on issues related mainly to the effects of occupational exposure to low-frequency airborne ultrasound. It is worth noting that recently an excellent broad overview of bio-effects and safety of low-intensity, low-frequency ultrasonic exposures has been prepared by Ahmadi et al. [3], whereas mechanical and biological effects of ultrasound used for medical diagnostic and therapeutic purposes have been reviewed by Izadifar et al. [4].

\section{Sources of low-frequency airborne ultrasound}

For several decades, low-frequency ultrasound has been widely used in industry, medicine, commerce, military service and the home. Industrial and domestic applications of low-frequency ultrasound cover a varied range of uses, including cleaning, drilling, plastic and metal welding, emulsification, dispersion, and homogenization ranging and navigation, as well as numerous domestic products, 
such as pest repellers, remote control, burglar alarms, automatic camera focusing devices, etc. [2,5].

In turn, medical applications comprise a number of therapeutic procedures such as sonophoresis (transdermal drug delivery), dentistry, eye surgery, body contouring and sonothrombolysis (eliminating blood clots) [3]. Moreover, devices emitting low-frequency ultrasound (e.g., pest deterrents or public address voice alarm systems) are also widely used in public places such as railway stations, pubs, restaurants, schools, sport facilities, etc. Therefore, there has been a massive increase in exposure to ultrasound in the surrounding environment, including residential, recreational and occupational settings [6,7].

Ultrasonic devices used in technological processes (including washing, drilling, soldering emulsification, and mixing) generate ultrasound not only at the operating frequency, but also at its harmonics. Moreover, these processes are generally carried out using ultrasound at high intensities that cause cavitation which is responsible for additional emissions of high-level audible noise [2].

Low-frequency ultrasound (approx. $<40 \mathrm{kHz}$ ) propagating in the air and high-frequency audible sound (approx. $>10 \mathrm{kHz}$ ) are referred to as ultrasonic noise [8]. In other words, ultrasonic noise is defined as broadband noise containing very high-frequency audible and low-frequency ultrasonic components (including one-third octave bands of $10-40 \mathrm{kHz}$ ). The main sources of ultrasonic noise in the work environment are the above mentioned ultrasonic devices. However, there are also a number of machines or processes unintentionally generating ultrasonic noise, such as compressors, pneumatic tools, high-speed machinery, such as planers, millers, grinders, circular saws, some textile machinery as well as plasma arc welding and airacetylene welding [9-12].

Recently, Leighton [6] introduced 3 categories of human exposure to low-frequency ultrasound in the air:
- category 1 - ultrasonic noise exposure - takes place when some process or device (e.g., a jet engine) generates ultrasound as a by-product of its operation;

- category 2 - unintended ultrasonic exposure - takes place when some process (e.g., an ultrasonic cleaning bath) requires the generation of a specific ultrasonic signal as a key to completing its task, but in addition to insonifying its inanimate target, it also unintentionally exposes a human or an animal to ultrasound;

- category 3 - deliberate ultrasonic exposure - occurs when devices (e.g., pest deterrents) are designed to expose humans and/or animals to ultrasound in the air in order to elicit some subjective response (whether or not the target is the intended species or demographic).

According to the aforesaid classification, exposure categories 1 and 2 are the most common in occupational settings [9-12].

The overall objective of the study was to present the current state of the art in the field of auditory and non-auditory effects of high-frequency sound and low-frequency airborne ultrasound on people, especially in occupational settings.

\section{METHODS}

This review includes papers concerning the impact of high-frequency sound and low-frequency airborne ultrasound on people, published in 1948-2018. The papers were identified by literature search of all accessible medical and other databases (WOS, BCI, CCC, DRCI, DIIDW, KJD, MEDLINE, RSCI, SCIELO and ZOOREC), using the following criterion: [TS = ((ultrasound * OR ultrasonic) AND noise AND occupational)].

Generally, a huge number of papers $(\mathrm{N}=451)$ complied with the aforesaid criteria. However, after the preliminary hand-search, 38 papers were selected for further analysis. In turn, the latter list was supplemented by earlier publications, to which articles from the aforesaid list have repeatedly referred. 


\section{RESULTS}

According to literature data, the first reported observation of harmful biological effects of ultrasound took place in April 1917, during underwater tests in a lake of a $150 \mathrm{kHz}$ and $1 \mathrm{~kW}$ ultrasonic transducers, when the immediate death of fish swimming near the acoustic beam was noted [3]. However, low-frequency airborne ultrasound was recognized as a potential health problem in the late 1940s when jet aircrafts, namely jet engines, were introduced, and the term of "ultrasonic sickness" was coined to cover subjective symptoms (such as excessive fatigue, headaches, nausea and vomiting) reported by a number of subjects working in their neighborhood [13]. At that time, Allen et al. [14] observed a loss of the sense of equilibrium or slight dizziness due to exposure to intense (160-165 dB) high-frequency audible sound, whereas Dickson and Watson in 1949, as well as Dickson and Chadwick in 1951, (as cited in [15]) reported unsteadiness and dizziness among workers exposed (without hearing protection) to noise from air intake of jet engines. According to the latter authors, this might be due to vestibular disturbances caused by intense acoustic simulation.

However, the published analyses of the jet engines noise did not show the presence of high-level low-frequency airborne ultrasound, and Parrack [16] finally stated that ultrasonic sickness was "largely psychosomatic in origin" although the other effects had been real enough. Thus, then followed a period when the possibility of an adverse impact of exposure to low-frequency ultrasound was dismissed [13]. Consequently, no systematic studies on ultrasound effects were carried out until the late 1950s. A note of caution was introduced in the mid-1950s by Crawford (as cited in [15]), who reported that a number of laboratory workers had complained about unusual fatigue, loss of equilibrium, nausea and headaches which persisted after the exposure had ceased, and "some loss of hearing in the upper audible frequencies."
Since that time, a number of studies on the effects of low-frequency airborne ultrasound have been conducted, many of which have focused on occupational exposures. Nevertheless, according to their results, the potential effects of low-frequency airborne ultrasound have been classified as auditory effects and non-auditory effects, including physiological, thermal, and subjective effects.

Recently, special attention has been paid to potential harmful effects of human exposure to airborne ultrasound in public places (including railway stations, museums, libraries, schools and sports facilities) due to the common usage of devices operating at ultrasonic frequencies such as pest repellers, remote control, etc. [6,7].

\section{Auditory effects of low-frequency airborne ultrasound}

For decades, the golden standard for assessing hearing acuity was the conventional pure-tone audiometry in the frequency range of $125-8000 \mathrm{~Hz}$. More recently, extended high-frequency audiometry has been recognized as a more sensitive tool for the identification of early signs of noise-induced hearing loss and age-related hearing loss [17,18]. An adverse impact of (audible) noise on hearing is well documented and usually measured as a temporary threshold shift (TTS) or a permanent threshold shift (PTS). However, the negative impact of exposure to ultrasound on hearing acuity has been relatively less evident to date.

\section{Temporary and permanent threshold shifts}

In very early studies, low-frequency airborne ultrasound was reported to generate audible subharmonics in human and animal ears, and was suggested as the cause of auditory effects [2]. Such subharmonic distortion products were reported in the cochlear-microphonic potentials of guinea pigs, and were also monitored in the sound field in front of the eardrum using a probe-tube microphone $[19,20]$. They were believed to result from non-linear amplitude distortion of the eardrum, and they appeared at a magnitude of 
the same order as that of fundamental frequency [21]. Furthermore, it was assumed that if noise exposure was not aimed to cause TTS, then it could not produce PTS [22]. However, laboratory and field studies carried out in the 1960s showed mixed results concerning the auditory effects of low-frequency airborne ultrasound.

For example, Acton and Carson [15] determined the audiometric hearing threshold levels (HTLs) (in the frequency range of $2-12 \mathrm{kHz}$ ) before and after the exposure to noise over an 8-h working day in 16 operators of ultrasonic devices emitting broadband noise, comprising ultrasonic components (at a sound pressure level [SPL] up to $110 \mathrm{~dB}$ in the one-third octave bands of 20-25 kHz). No significant TTS was observed. Thus, based on the aforesaid assumption concerning TTS and PTS, they concluded that hearing damage due to exposure from industrial ultrasonic devices (washers, welders, drills) was unlikely [15].

A parallel retrospective study by Knight [23], conducted on a group of 18 young male operators of ultrasonic devices (with the tenure up to 8 years), showed that their HTLs over the entire frequency range $(250-8000 \mathrm{~Hz})$ were only by $2-7 \mathrm{~dB}$ worse (higher) than those of the control group (20 hospital staff members of similar age but without any noise exposure). In addition, no abnormal vestibular function test (caloric test) results were noted [23]. Thus, these results do not support the thesis that hearing loss is solely attributable to ultrasonic exposure. For comparison, Milkov et al. [24] noted about 10-15 dB higher HTLs at 10, 12 and $14 \mathrm{kHz}$ among operators of ultrasonic devices, as compared to the control group.

In turn, according to the results of the experiment conducted by Grigor'eva [25], a 1-h exposure to ultrasound at a frequency of $20 \mathrm{kHz}$ and the SPL of $110-115 \mathrm{~dB}$ did not cause any significant temporary changes in the hearing thresholds in the frequency range of $0.25-10 \mathrm{kHz}$. When the same subjects were exposed for $1 \mathrm{~h}$ to a $5 \mathrm{kHz}$ tone at $90 \mathrm{~dB}$, a considerable TTS was observed. On that basis, it is concluded that airborne ultrasound is less hazardous than audible sound, and a limit of $120 \mathrm{~dB}$ was proposed for ultrasonic exposures at $\geq 20 \mathrm{kHz}$ frequencies [25]. Contrary to Grigor'eva [25], some other authors [16,26] have observed TTS due to ultrasonic exposure under laboratory conditions. For example, Parrack [16] showed that after 5-min exposure to ultrasound at discrete frequencies of $17-37 \mathrm{kHz}$ and the SPL of $148-154 \mathrm{~dB}$, the subjects' hearing acuity was temporarily reduced at the subharmonics of one-half of the fundamental and occasionally at lower subharmonic frequencies. Moreover, TTS usually $<20 \mathrm{~dB}$ rapidly recovered to the pre-exposure hearing acuity. On this basis, it was concluded that ultrasound should be harmless to the human ear until the octave band or one-third octave band levels approach $140 \mathrm{~dB}$. In turn, Dobroserdov [26] observed TTS at 14 and $15 \mathrm{kHz}$ (of about $11-17 \mathrm{~dB}$ or $5-10 \mathrm{~dB}$ ) after 3-10 times repeated 1-h exposure to ultrasound at $20.6 \mathrm{kHz}$ and the SPL of $120 \mathrm{~dB}$. For comparison, high-frequency audible noise at 80 or $100 \mathrm{~dB}$ caused TTS, on average, equal to $12 \mathrm{~dB}$ or $20 \mathrm{~dB}$, respectively.

Slightly later, Grzesik and Pluta [27] analyzed the HTLs in the frequency range of $0.5-20 \mathrm{kHz}$ in 55 operators of ultrasonic welders and cleaners (with the tenure of 7-17 years) as compared to the control group (comprising 189 otologically normal subjects without occupational exposure to noise). No significant differences in HTLs between the study subjects and controls were observed in the frequency range of $0.5-8 \mathrm{kHz}$. However, a statistically significant increase in the HTLs in the frequency range of $10-20 \mathrm{kHz}$ was noted among operators of ultrasonic devices, and a decreasing number of subjects responding to stimuli at the highest audible frequencies during hearing tests was observed.

In the follow up study aimed at elucidating the hearing loss process over a period of 3 years among 26 ultrasonic workers, Grzesik and Pluta [28] suggested that the PTS of approximately $1 \mathrm{~dB} /$ year occurred in the frequency range of $13-17 \mathrm{kHz}$ due to the noise exposure from ultrasonic 
devices (at SPLs of $80-102 \mathrm{~dB}$ and $100-116 \mathrm{~dB}$ in the frequency range of $10-18 \mathrm{kHz}$, and $\geq 20 \mathrm{kHz}$, respectively). They also found that the fraction of ears responding to the highest frequencies decreased by about $10 \%$ per year with a $1 \mathrm{kHz}$ increase in the frequency range of $13-19 \mathrm{kHz}$, and concluded that the higher the frequency to which an ear was sensitive, the greater its susceptibility to high-frequency noise.

Further investigation by Grzesik and Pluta [29], conducted among 106 operators of ultrasonic devices, confirmed that occupational exposure to high-frequency noise at SPLs of $>80 \mathrm{~dB}$ in the one-third octave bands of $10-16 \mathrm{kHz}$ might cause hearing loss in the frequency range of $10-16 \mathrm{kHz}$.

Nearly 30 years later, Macca et al. [30] tested 24 industrial workers exposed to ultrasonic noise, 113 industrial noiseexposed workers and 148 non-noise-exposed subjects using both conventional pure tone audiometry $(0.125-8 \mathrm{kHz})$ and extended high-frequency audiometry $(9-18 \mathrm{kHz})$. They found that the subjects exposed to ultrasonic noise (i.e., operators of ultrasonic welders, cleaning tanks or textile machines) had significantly higher (worse) hearing thresholds than the non-exposed ones at high frequencies, being the greatest from $10-14 \mathrm{kHz}$ and considerably evident after 5 years of exposure. For comparison, the noise exposure group had significantly higher hearing thresholds than the non-exposed group at the conventional frequencies of $4 \mathrm{kHz}$ and $6 \mathrm{kHz}$, and at the high frequency of $14 \mathrm{kHz}$. These results led the latter authors to the conclusion that ultrasonic exposure caused hearing loss in the frequency range of $9-18 \mathrm{kHz}$, and that this deficit might appear already after 5 years of occupational exposure, being likely to worsen with continued exposure and age. However, the general conclusion of this study was that age was the primary predictor, and noise and ultrasound exposure were the secondary predictors of hearing thresholds in the extended highfrequency range.

More recently, Dudarewicz et al. [31] obtained very similar results. In the latter study, hearing tests (i.e., conven- tional pure tone audiometry and extended high-frequency audiometry) were performed in 90 operators of ultrasonic welders, together with SPL measurements in the audible and ultrasonic frequency range. The reference group consisted of 156 subjects exposed to industrial noise (without ultrasonic components) at a similar A-weighted SPL (equal to approx. $82 \mathrm{~dB}$ ), adjusted for age, gender and tenure.

Industrial workers were exposed to audible and ultrasonic noise at the A-weighted daily noise exposure level of $80.6 \pm 2.9 \mathrm{~dB}$ and the equivalent-continuous SPLs (normalized to a nominal 8-h working day) in the one-third octave bands centered at $10-20 \mathrm{kHz}$ and $25-40 \mathrm{kHz}$, in the range of 40-90 and 85-110 dB, respectively. Generally, the Polish maximum admissible intensity (MAI) values for the ultrasonic noise were only exceeded in approx. $35 \%$ of cases, while for the audible noise in about $23 \%$ of cases (Table 1). It was found that in the frequency range of $0.5-6 \mathrm{kHz}$, HTLs were similar in both groups, while in the frequency range of $8-12.5 \mathrm{kHz}$, the workers exposed to ultrasonic noise had higher (worse) HTLs. Thus, it was suggested that the differences in hearing thresholds (at extended high frequencies) between both groups might have resulted from the differences in the spectral composition of noise, which supports the need for further research.

A few years earlier, Pawlaczyk-Łuszczyńska et al. [32] also studied the hearing condition among the operators of ultrasonic welders. However, they only analyzed the results of the standard pure-tone audiometry (PTA) collected from 25 workers, mainly females, aged 23-58 years, exposed for 2-13 years to ultrasonic noise. (Sound pressure levels in the one-third octave bands of $10-40 \mathrm{kHz}$ exceeded the Polish MAI values in $60 \%$ of the analyzed work posts). The first examination was performed up to 9.5 years after the commencement of employment, while intervals between tests ranged 0.8-7.4 years. Generally, no significant progress of hearing impairment (assessed us- 


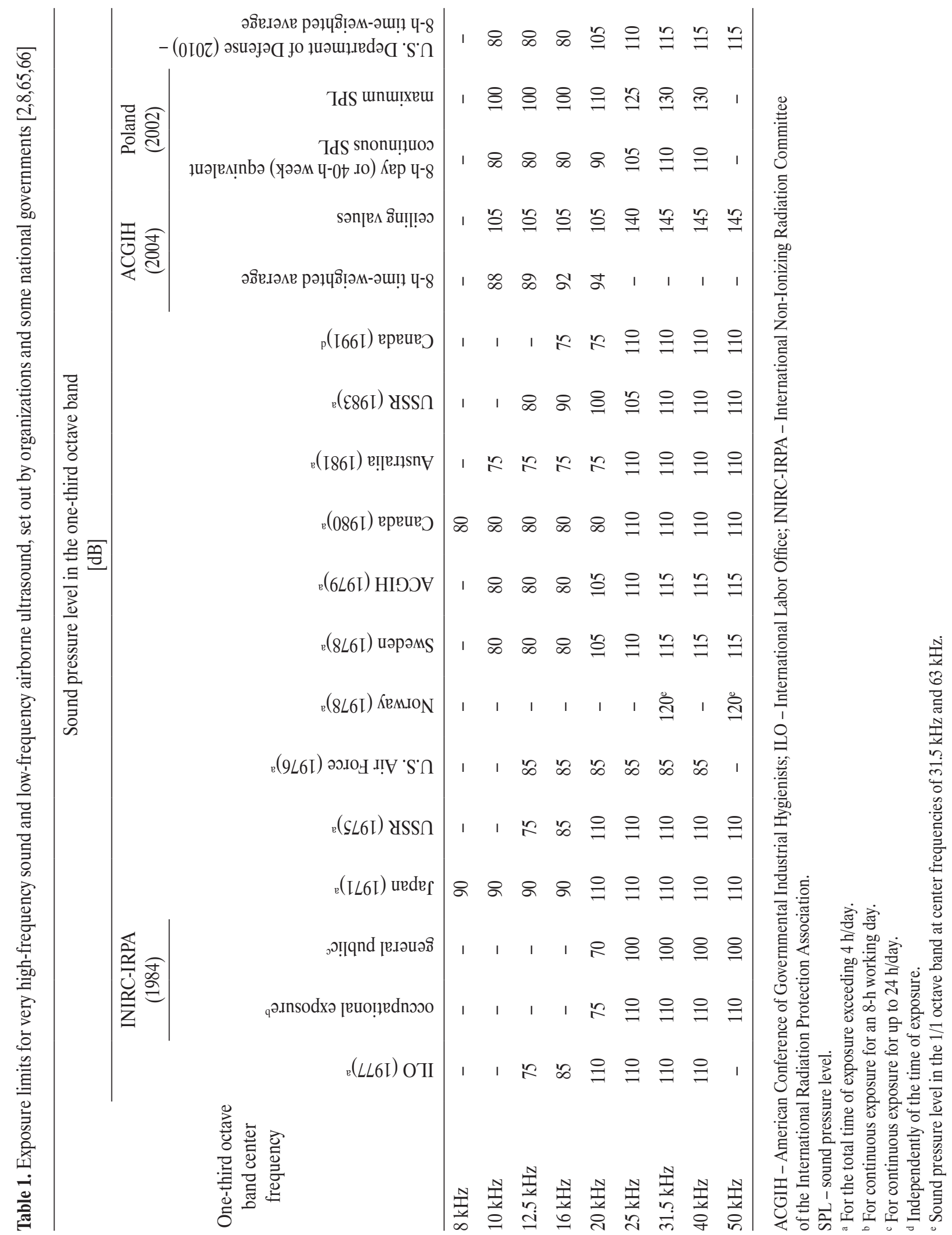


ing PTA) was noted in the operators of ultrasonic welders. In particular, the starting number $(\mathrm{N}=19)$ of normal audiograms in the frequency range of $1-8 \mathrm{kHz}$ (the HTL of $\leq 20 \mathrm{~dB}$ HL) did not decrease after exposure to ultrasonic noise. Moreover, the results of the first and the last hearing examinations did not differ significantly for the majority of the frequencies, excluding $500 \mathrm{~Hz}$ and $2000 \mathrm{~Hz}$ for the left and right ear, respectively [32].

Recently, Chopra et al. [33] carried out a series of hearing tests (including standard pure tone audiometry and otoacoustic emission tests) among 60 dental clinicians to evaluate the possible negative auditory effects developed immediately after the usage of ultrasonic scalers operating at $25 \mathrm{kHz}$. The SPLs generated by 1 scaler in usage remained within the range of 84-91 dB and exceeded $137 \mathrm{~dB}$ for multiple devices. The obtained results indicated a significant post-exposure reduction in the overall hearing capacity of clinicians. Moreover, in addition to the significant temporary shift in hearing thresholds and a reduction of otoacoustic emissions, some dentists reported a mild ear pain or tinnitus [33].

Forty years ago, Möller et al. [34] observed TTS in 8 out of 20 subjects following a 5-min ultrasonic scaling procedure. Unilateral changes of $10-20 \mathrm{~dB}$ in the frequency range of $3-10 \mathrm{kHz}$ were demonstrated in these patients, 3 of whom had bilateral tinnitus. However, according to

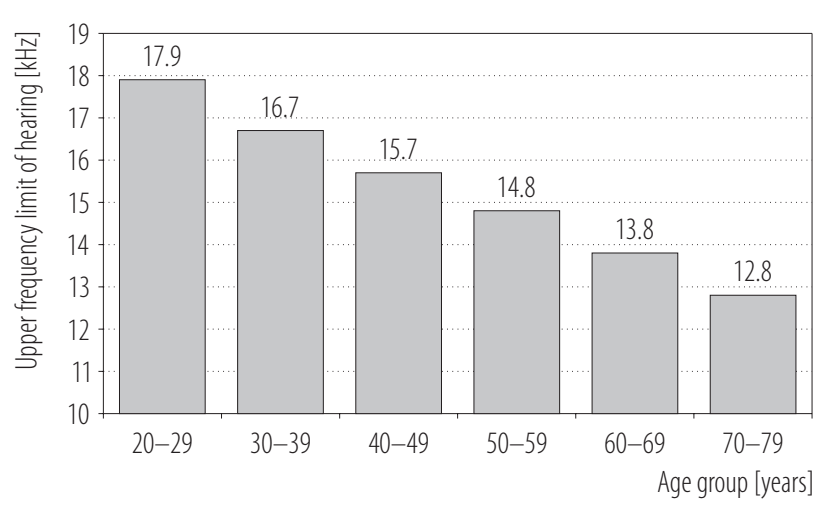

Figure 1. The upper frequency limits of hearing in various age groups - these values represent the central tendency of a number of studies analyzed by Lawton [38] the results of other (earlier) investigations, the harmful impact of ultrasonic scalers on hearing was not found to be fully obvious $[35,36]$.

For example, Rahko et al. [35] did not find any significant difference in the hearing ability between the dental personnel and controls. In turn, a study by Wilson et al. [36] comprising 40 dental hygienists did not show any significant differences in HTLs between high- and low-ultrasonic scaler users in the whole frequency range of $500-8000 \mathrm{~Hz}$, excluding $3000 \mathrm{~Hz}$. Based on these outcomes, it was concluded that ultrasonic noise might affect dental hygienists' hearing only at $3000 \mathrm{~Hz}$ [36].

\section{Upper frequency limit of hearing}

Young people can usually hear sounds at frequencies up to $20 \mathrm{kHz}$. However, both the upper frequency limit of hearing and hearing sensitivity decrease with age [37]. Lawton [38] examined a number of reports on hearing tests in the very high frequencies, in order to extract information on the aforesaid age-related changes. Figure 1 presents the expected upper frequency limits in people depending on their age, while Figure 2 shows the hearing threshold shift in various age groups relative to the 20-29 year old baseline [38]. Over the years, hearing thresholds have been measured by a number of research teams; however, not much data on the auditory perception of $>20 \mathrm{kHz}$ are available [6]. For example, Henry and Fast [39] used a sound delivery system that could provide constant stimuli up to $124 \mathrm{~dB}$ and found that a majority of listeners in their study perceived tones up to $24 \mathrm{kHz}$. They also noted that HTLs increased abruptly as the signal frequency changed from about 14 to $20 \mathrm{kHz}$, while at $>20 \mathrm{kHz}$ the increase was less rapid. About 20 years later, Ashihara et al. [40] also managed to determine hearing thresholds for a $24 \mathrm{kHz}$ tone in a number of participants, although the highest presentation level of stimuli in their study was $99 \mathrm{~dB}$ SPL. In another study, the researchers measured hearing thresholds for pure tones of $16-30 \mathrm{kHz}$ (using an adaptive method) and 
showed that some people could detect tones up to $28 \mathrm{kHz}$ at the SPL of $>100 \mathrm{~dB}$. It is worth noting that no threshold was obtained for a $30 \mathrm{kHz}$ tone, while it was determined for 3 out of 32 ears at $28 \mathrm{kHz}$. Moreover, the threshold values at frequencies of $\geq 24 \mathrm{kHz}$ were always recorded at the SPL of $>90 \mathrm{~dB}$ [41].

Generally, it is believed that hearing thresholds and perception during stimulation via air conduction could only be detected up to $40 \mathrm{kHz}$ [42]. Stimulation by bone conduction is much more effective. Signals up to $95 \mathrm{kHz}$ were found to cause a hearing sensation [42]. Furthermore, some attempts have been made to improve objective investigations of ultrasound perception.

For example, Fujioka et al. [43] used magnetoencephalography (MEG) for studying brain activity in response to low-frequency airborne ultrasound up to $40 \mathrm{kHz}$, and they could not find any response at $20-40 \mathrm{kHz}$. Contrary to the aforesaid results, Hosoi et al. [44] measured the N1m brain activity components for tone bursts up to $40 \mathrm{kHz}$ using MEG, but their stimuli were presented via bone conduction. In turn, Oohashi et al. [45] demonstrated the impact of ultrasonic frequencies on hearing by using music with extraordinarily high-frequency spectral components as a stimulus by applying electroencephalography (EEG) and positron emission tomography (PET).

More recently, Kühler et al. [46] investigated the perception of sound and the activation of the auditory cortex by means of sounds at high or ultrasound frequencies using audiological methods and brain imaging. They determined hearing thresholds up to a frequency of $24.2 \mathrm{kHz}$ in a group of 26 test subjects, and found that these threshold values increased strongly with increasing frequency up to approx. $21 \mathrm{kHz}$, followed by a range with a smaller slope toward $24 \mathrm{kHz}$. The number of subjects for whom hearing thresholds could be obtained decreased dramatically at frequencies of $>21 \mathrm{kHz}$ [46].

Brain activation was then measured by means of MEG and functional magnetic resonance imaging (fMRI), and with

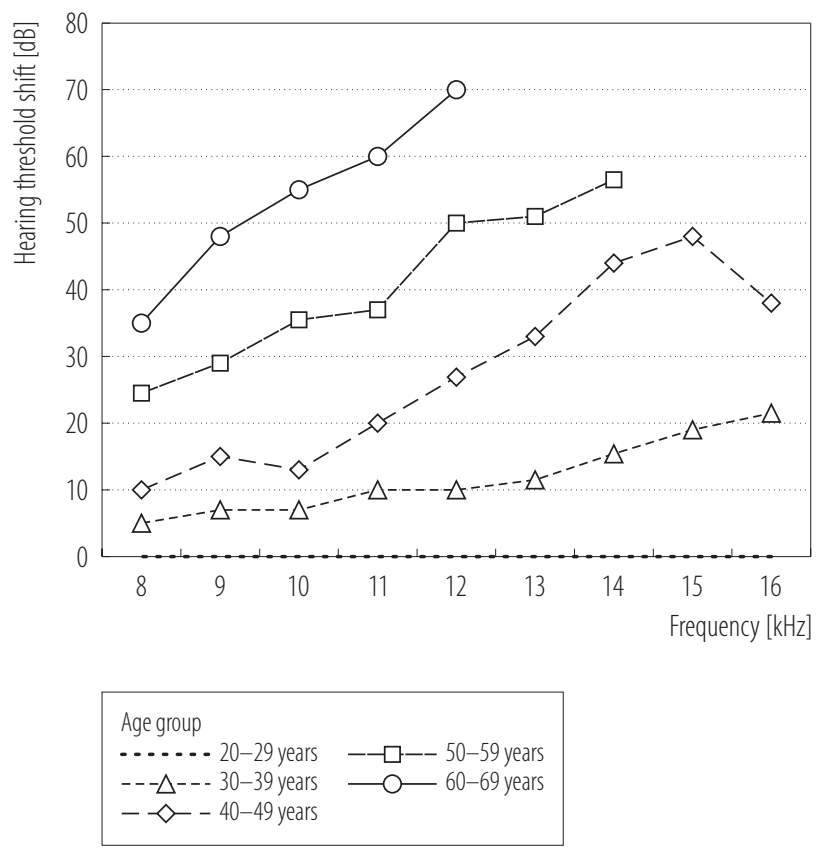

Figure 2. Hearing threshold shift by age group, relative to subjects aged 20-29 years - these data result from Lawton's critical analysis of several studies on the hearing threshold in the extended high-frequency range [38]

acoustic stimuli at the same frequencies, with SPLs above and below the individual threshold. However, no auditory cortex activation was found for levels below the threshold. Although the test subjects reported audible sounds above the threshold, no brain activity was identified in the abovethreshold case under current experimental conditions except at the highest sensation level, which was presented at the lowest test frequency [46]. Thus, the mechanisms of ultrasound perception are still unclear and need further studies.

\section{Subjective symptoms}

Several subjective effects have been reported as a result of exposure to low-frequency airborne ultrasound. In particular, some workers exposed to industrial ultrasonic sources, such as ultrasonic cleaners and drills, complained of fatigue, headaches, nausea, tinnitus, and vomiting $[15,21,22,47-49]$. 
For example, Skillern [50] measured the noise spectra from a number of ultrasonic devices and found that only operators of devices emitting SPLs of $>80 \mathrm{~dB}$ (in onethird octave bands of $10-31.5 \mathrm{kHz}$ ) complained about work-related subjective effects. He also attempted to correlate these effects with frequency, and erroneously concluded that the human ear was sensitive to a narrow band of frequencies centered at $25 \mathrm{kHz}$.

At the same time, Acton and Carson [15] analyzed the prevalence of adverse reactions among 18 persons subjected to ultrasonic noise, including 9 young females exposed to the bank of washers or laboratory-type washers, and 7 older men with a history of noise exposure, working with ultrasonic drills. They showed that only young females who had normal hearing in the upper frequency range (2-12 kHz) complained of fatigue, headaches, nausea and tinnitus, persisting for some hours after the end of exposure. However, these effects disappeared when the bank of washers (operating at $20 \mathrm{kHz}$ [95 dB] with harmonics at $40 \mathrm{kHz}[115 \mathrm{~dB}]$ ) was in an enclosure and emissions decreased by $10 \mathrm{~dB}$ [15].

In the subsequent laboratory experiment, during which the subjects were exposed to noise with dominant frequencies of $16-40 \mathrm{kHz}$ produced by the Galton whistle, the aforesaid authors also noted subjective symptoms [15]. However, this time only 2 persons with normal hearing experienced fullness in the ear followed by a headache, while the subject who was unable to hear at $16 \mathrm{kHz}$ was unaffected. Furthermore, (inaudible) ultrasound at $20 \mathrm{kHz}$ and the SPL of $101 \mathrm{~dB}$ caused no subjective effects, while high-frequency audible sound of $78 \mathrm{~dB}$ at $16 \mathrm{kHz}$ produced such effects (in the aforesaid 2 subjects). These findings led Acton and Carson to the conclusion that subjective effects were not caused by low-frequency ultrasound, but they were due to high levels of high-frequency audible noise usually produced as a by-product of industrial ultrasonic processes, especially those involving cavitation [15]. The authors supported this conclusion by emphasizing that women complained about these effects to a higher extent than men. As the male workers were older and all had a history of noise exposure as well as high-frequency hearing loss, they assumed that the exposures were largely inaudible to many of the men [15].

A detailed analysis of Acton and Carson's data showed that subjective effects were not found if SPLs were $<75 \mathrm{~dB}$ and $110 \mathrm{~dB}$ in the one-third octave bands of $\leq 16 \mathrm{kHz}$ and $\geq 20 \mathrm{kHz}$, respectively [15,22]. The aforesaid criterion, consistent with Skillern's findings [50], had been initially suggested by Acton as an exposure limit. Later, this criterion was verified. In the revised version, the limit value of $75 \mathrm{~dB}$ was extended to include the one-third octave band of $20 \mathrm{kHz}$, since Acton found that subjective effects could still occur below $110 \mathrm{~dB}$ in the one-third octave band of $20 \mathrm{kHz}$ [47]. Such a decision was explained by the lower- and upper-frequency limits of the one-third octave band centered at $20 \mathrm{kHz}$, which are $17.6 \mathrm{kHz}$ and $22.5 \mathrm{kHz}$. The lower end of this frequency band was within the upper end of the audible frequency range of a considerable proportion of the population and, therefore, subjective effects could occur at relatively low levels.

Further studies also provided more evidence on the prevalence of subjective symptoms. In 1977, Crabtree and Forshaw [48] reported that the noise from ultrasonic cleaners caused nausea, headaches, tinnitus and fatigue. At the SPL of approx. $105 \mathrm{~dB}$ (in the one-third octave band of $20 \mathrm{kHz}$ ), severe auditory and subjective effects, as mentioned above, as well as an unpleasant sensation of fullness or pressure in the ears were reported by the Canadian Forces personnel in the vicinity of ultrasonic cleaning tanks [48].

In 1983, Acton [49] confirmed a sensation of fullness and pressure in the ears, and added tinnitus to the list of symptoms reported by workers exposed to ultrasound. On the other hand, Herman and Powell [51] analyzed ultrasound effects from sources outside the usual industrial context such as intruder alarms or ultrasonic dog 
repellers. They noted that ultrasonic beams (with the frequency of $20-40 \mathrm{kHz}$ and SPLs up to $90.5-93 \mathrm{~dB}$ ) used in the alarm systems to detect the presence of an intruder, were reported as being audible to some individuals, and capable of causing headaches amongst staff and extreme annoyance in customers. In turn, the reaction of people in the case of the ultrasonic dog repeller (emitting a signal of a maximum level of $108 \mathrm{~dB}$ at $16 \mathrm{kHz}$ in a distance of $1.5 \mathrm{~m}$ ), ranged from no perception at any distance from this device, to severe discomfort in the ears about $12.5 \mathrm{~m}$ away, in another room [51]. According to a later study by Smith et al. [52], signals at frequencies of $>17 \mathrm{kHz}$ and the level of $>70 \mathrm{~dB}$ may cause negative symptoms among exposed workers, such as excessive fatigue, nausea, fullness in the ears and headaches. In turn, Holmberg et al. [53] exposed 10 workers to 2-min bursts of noise from an ultrasonic washer at the A-weighted SPLs of $72 \mathrm{~dB}, 80 \mathrm{~dB}$ and $96 \mathrm{~dB}$, when performing a proof-reading task, and required them to rate annoyance (the mental effect) and discomfort (the effect located at the ear). They did not find any differences between noise annoyance and discomfort ratings. However, the ratings seemed to be high, thus the authors recommended to avoid occupational exposures to noise from such ultrasonic devices at the A-weighted SPL of $>70 \mathrm{~dB}$ [53].

Over 10 years later, Pawlaczyk-Łuszczyńska et al. [32] studied the impact of ultrasonic noise on 25 operators of ultrasonic welding machines, mainly women (aged $20-56$ years), and noted that $29.4 \%$ of the workers did not report any complaints related to noise at their workplaces. A number of them reported fatigue $(36.8 \%)$, headaches $(12.1 \%)$, drowsiness $(5.3 \%)$, dizziness $(5.3 \%)$ and palpitations $(5.3 \%)$. The workers described noise as loud $(52.6 \%)$, unsteady (44.4\%), sharp and unpleasant $(44.4 \%)$, annoying $(36.8 \%)$, irritating $(36.8 \%)$ and interfering with work (16.7\%). In addition, a small fraction $(5.6 \%)$ of the workers complained that noise made the concentration impossible.
More recently, the above mentioned Macca et al. [30], when analyzing HTLs among workers exposed to ultrasonic noise or (audible) noise (compared to non-noiseexposed subjects), were also studying the prevalence of work-related effects such as asthenia, headaches, gastrointestinal symptoms, tinnitus, a sensation of fullness in the ears, low hearing, a loss of equilibrium, vertigo and tingling in the hands and legs. They noted that almost all of the aforesaid symptoms occurred mainly in workers exposed to noise, apart from asthenia, gastrointestinal disorders and vertigo. This group also had statistically significant problems of tinnitus (as compared to the non-noiseexposed group), while asthenia (a loss or lack of bodily strength) and vertigo were more frequently reported by subjects exposed to ultrasonic noise. Furthermore, significant correlations were also obtained between tinnitus, a sensation of fullness in the ears and hypoacusis in subjects exposed to audible noise [30]. Leighton's subsequent recalculations of the Macca et al. data additionally revealed a significant increase in the "tingling in the limbs" effect in the ultrasound-exposed group as compared to the non-noise-exposed group [6].

As mentioned above, at the same time, Chopra et al. [33] studied both auditory and non-auditory effects among 60 dental clinicians due to the usage of ultrasonic scalers. In terms of the non-auditory effects, they asked clinicians to report symptoms such as irritation, headache, fatigue, pain in the hand, fingers, wrist or back, dizziness or ringing sensations in the ears. The authors found that 4 out of 60 clinicians reported mild ear pain with tinnitus, $12 \mathrm{had}$ a ringing sensation in the ear or tinnitus, 3 felt irritated, 1 had slight headaches, and 27 reported fatigue in the fingers and palm. One clinician also reported back pain. The post-scaling pulse rate was also increased by an average of 2-4 units from the baseline value in $67 \%$ of the clinicians. In the authors' opinion, these subjective effects are slow but definite reactions that mimic a physiological stress-like condition in the body. Most reactions are 
asymptomatic and individuals usually lose any awareness of them after some time. Nonetheless, further studies are needed to confirm that ultrasonic scalers have a significant role in the development of non-auditory dysfunctions [33].

Due to an increasing exposure of the public to very highfrequency sound and/or low-frequency airborne ultrasound from such devices as the Mosquito teen repellers [6,7], and media reports of discomfort and headaches resulting from such exposures, as well as the complaints made by several members of the public, a number of "new" studies have been carried out within a past few years [54-57]. For example, Ueda et al. [54] assessed the symptoms experienced by workers and young users visiting a restaurant where they were exposed to ultrasound (at $20 \mathrm{kHz}$ and the SPL of $90-130 \mathrm{~dB}$ ) emitted by a rodent repeller. The initial study group comprised 35 participants in total, including 29 college students and 6 subjects (in their late 20s and 50s). Finally, only those participants who heard a signal from the rodent repeller were asked to rate their reactions and symptoms related to ultrasound exposure [54].

It was shown that younger participants more clearly than elderly workers recognized the high-frequency sound from the rodent repeller. Furthermore, most of the subjects who recognized the high-frequency sound gave negative evaluations, such as "unpleasant," "noisy," "having a headache or an earache," and so on.

In another, more recent investigation by van Wieringen and Glorieux [55], potential adverse effects of the very high-frequency audible and/or ultrasound signals emitted by a repeller were evaluated perceptually by 25 young and 25 middle-aged persons, with normal hearing. The study subjects were exposed to 8 various experimental conditions in random order, including dummy conditions (no signal) and immediately after each 20-min exposure assessed their reactions to the signal using a questionnaire taking into consideration the subjective effects reported in earlier studies. Frequency analyses demonstrated that, besides generating frequency modulated sound in the expected frequency ranges, a weak but audible sound in the range of $4-5 \mathrm{kHz}$ was present.

The obtained results indicated that a short-term exposure to acoustic signals (at relatively low SPLs ranging 40-70 dB) emitted by a repeller did not lead to any significant adverse effects. Yet, when the signal was heard, as it frequently happened for the younger population in the 2 lower frequency settings $(12-14 \mathrm{kHz}, 25-25 \mathrm{kHz})$, and with 2 sources emitting, it was perceived as disturbing by several participants. However, given the increased usage of ultrasonic devices and the much longer exposure to high frequency and ultrasound in domestic settings, the authors could not conclude that exposure to ultrasound is less harmful than to audible sound until more research has been done [55].

The aim of another recent study by Flechter et al. [56] was to establish whether the exposure to very high-frequency sound or/and ultrasound (VHFS/US) at the levels that may be encountered in public spaces provokes adverse symptoms to a greater extent than exposure to a reference sound of $1 \mathrm{kHz}$. For this purpose, the participants were subjected to VHFS/US (at frequencies of 13.5-20 kHz and SPLs of $82-92 \mathrm{~dB}$ ) and to a $1 \mathrm{kHz}$ reference stimulus, both at $25 \mathrm{~dB}$ above their hearing threshold. The very high-frequency sound and the reference stimuli were presented 4 times, each time for $3 \mathrm{~min}$, during which the subjects performed a sustained attention task, rated their symptom severity, and had their galvanic skin response (GSR) measured to assess their level of anxiety. The primary outcome measure was their subjective rating of the overall discomfort. Two different participant groups were studied: symptomatic participants $(\mathrm{N}=10)$ who, prior to recruitment, reported experiencing some adverse effects which they attributed to VHFS/US, and asymptomatic participants $(\mathrm{N}=32)$ who did not report any previous adverse effects of VHFS/US. The adverse symptoms reported by the symptomatic participants in the group selection phase 
included nausea, pain or pressure in the ears or head, a sensation of light-headedness or dizziness, anxiety, annoyance, tiredness, and inability to concentrate [56].

In both groups, the overall discomfort ratings were higher in the VHFS/US conditions than in the reference conditions. In the symptomatic group only, difficulty concentrating and annoyance were also rated higher in the VHFS/US conditions than in the reference conditions. No significant physiological symptoms such as nausea, pain or tinnitus were found in either group for either stimulus conditions. Moreover, no difference between the 2 stimulus conditions was seen in performing the attention task or in average GSRs for either group. However, in conclusion, the authors emphasized that their findings could not be used to predict the outcomes of exposures at higher SPLs or longer durations [56].

In turn, another study by Flechter et al. [57], being a continuation of the previous one, was aimed to determine whether inaudible ultrasound could cause adverse symptoms compared to a sham exposure control condition (i.e., no exposure). A further objective was to study whether the expectation of ultrasound being present could provoke adverse symptoms (a nocebo response). The latter study was a double-blind trial investigating the effects of inaudible ultrasound at SPLs that might be faced by the general public. Likewise in the aforesaid study, both symptomatic $(\mathrm{N}=8)$ and asymptomatic $(\mathrm{N}=32)$ groups of participants were investigated. In addition, a case study was conducted involving a participant who had reported particularly strong effects to ultrasound in public places, based on answers to the pre-existing symptoms questionnaire. Generally, the ultrasound stimulus was a $20 \mathrm{kHz}$ tone presented continuously for $20 \mathrm{~min}$, set to at least $15 \mathrm{~dB}$ below the participants' detection threshold, giving a typical SPL of $84 \mathrm{~dB}$, excluding the case study when the $20 \mathrm{kHz}$ tone at the SPL of $94 \mathrm{~dB}$ (still $10 \mathrm{~dB}$ below the participant's HTL) was applied [57]. The study results provided no evidence that ultrasound provoked subjective symptoms such as nausea, pain, pres- sure or fullness in the ears, headaches, dizziness, anxiety and fatigue. However, they demonstrated small nocebo effects. Similar results were obtained from the case study with the participation of a person with high self-reported sensitivity to ultrasound. According to Flechter et al. [57], there were several possible reasons why the subjective symptoms reported by some people were not reproduced in their study. This may be due to the intensity or duration of the ultrasound stimulus, or strength of the nocebo stimulus. The authors also stated, on the one hand, that their findings could not be used to predict the outcomes of exposures to sounds that are audible to the individual in question, or to sounds with higher SPLs, longer durations, or different frequency content. On the hand, they stressed that ultrasound at the frequency of $20 \mathrm{kHz}$ and the SPL of $84 \mathrm{~dB}$ (i.e., the average level of acoustic stimulus in their study) would be audible for a considerable percentage of people, particularly young ones. Thus, subjective effects might be provoked in a number of subjects at the frequency and exposure levels used in the study [57].

\section{Thermal effects}

It has been suggested that the most probable mechanisms for the non-auditory effects of low-frequency airborne ultrasound on people are heating and acoustic cavitation [5]. Ultrasound energy is attenuated during wave propagation through the medium due to absorption and scattering effects. In turn, absorption in tissues causes a conversion of sound energy into heat. The significance of thermal effects increases with a rise in ultrasound frequency [3].

In the case of the acoustic cavitation, which can be seen as the growth and collapse of preexisting microbubbles under the influence of an ultrasonic field in a liquid medium, the most important parameters are the frequency and intensity of ultrasound, the time of exposure as well as the availability of the cavitation nuclei [3]. A decrease in frequency lowers the threshold for transient cavitation, and it also affects the cavitation nuclei size and, consequently, 
the location of the cavitation phenomena [3]. However, neither of these phenomena can occur at relatively low SPLs typical of occupational exposure to low-frequency airborne ultrasound. The examples of cavitation thresholds given by Neppiras [58] suggested that low-frequency airborne ultrasound at SPLs up to $190 \mathrm{~dB}$ would not cause cavitation.

In the 1940s-1950s, many studies were conducted on the effects of airborne ultrasound on mammals and insects; the observed effects were interpreted as having been caused by heating. In earlier animal studies, thermal effects were observed due to exposures at relatively high SPLs. For example, Allen et al. [14] noted the death of insects and mice as a result of excessive heating after exposure to ultrasound $(20 \mathrm{kHz})$ at SPLs of $160-165 \mathrm{~dB}$, lasting $10 \mathrm{~s}-3 \mathrm{~min}$. Body heating in mice was observed at the level of $>144 \mathrm{~dB}(18-20 \mathrm{kHz})$ [14]. In the case of the hairless strain mice, the same effect occurred at the SPL of $155 \mathrm{~dB}$, indicating that fur plays a role in absorbing energy [21,59].

The mismatch of acoustic impedance between air and the human skin tissue causes that the skin is a barrier protecting against the penetration of ultrasound energy from the air into the body. The absorption rate of the skin decreases with increasing frequency. Parrack [16] demonstrated that the absorption coefficient for furred rats at $20 \mathrm{kHz}$ was about 200 times higher than that of the human body surface, and that the difference was considerably reduced when the rat's fur was shaved off. Thus, the animal fur performs the function of matching the acoustic impedance of the body to the acoustic impedance of the air.

Animals have a much lower body weight compared to humans and a higher surface area-to weight ratio which consequently gives worse conditions for the distribution of heat energy, as compared to humans. Therefore, the effects observed in small laboratory animals cannot be directly extrapolated to humans.

First reports, written in 1948, on the thermal effects of ultrasound on the human body described burns on the hand skin between fingers from accidental exposure at the SPL of $165 \mathrm{~dB}$ (and $20 \mathrm{kHz}$ ) [13,14]. Local heating in the crevices between fingers caused burns almost instantly at these levels. Painful heating occurred after several seconds of exposure of broader surfaces such as the palm of the hand. At the same time, exposure to airborne ultrasound at SPLs of $140-150 \mathrm{~dB}$ caused vibrations of hair, particularly in the ear canals or nasal openings, and a simultaneous local warming in these areas [16].

In industrial studies, Grigor'eva [25] found the postexposure increase in the body temperature of $0.5^{\circ} \mathrm{C}$ in $40 \%$ of 20 operators of ultrasonic devices (with the tenure of $1-3$ years), and in some of them of $1-2^{\circ} \mathrm{C}$. In turn, Mączewski-Rowiński (as cited in [60]) reported cases of cataract among industrial workers exposed to low-frequency airborne ultrasound.

\section{Physiological changes}

In the studies involving small animals, mild biological changes have been reported during a prolonged exposure to airborne ultrasound with levels in the range of 95-130 dB at frequencies ranging 10-54 kHz [21].

Workers exposed to noise emitted by ultrasound devices suffered from increased neural excitability, irritation, memory problems and difficulties with concentration and learning [60]. Functional changes such as neurasthenia, cardiac neurosis, hypotension, heart rhythm disturbances (bradycardia) and adrenergic system disturbances were also observed [61,62].

The results of laboratory tests with young people exposed to ultrasound ( $21 \mathrm{kHz}$ and $110 \mathrm{~dB}, 3 \mathrm{~h} /$ day for $10-15$ days) and the combined effects of ultrasound and broadband audible noise (up to $10 \mathrm{kHz}$ and $75 \mathrm{~dB}$ ) indicated functional changes in the central nervous and cardiovascular systems [63].

No significant physiological changes were reported by Grigor'eva [25] in workers as a result of 1-h exposure to ultrasound at $20 \mathrm{kHz}$ and SPLs of $110-115 \mathrm{~dB}$. In turn, 


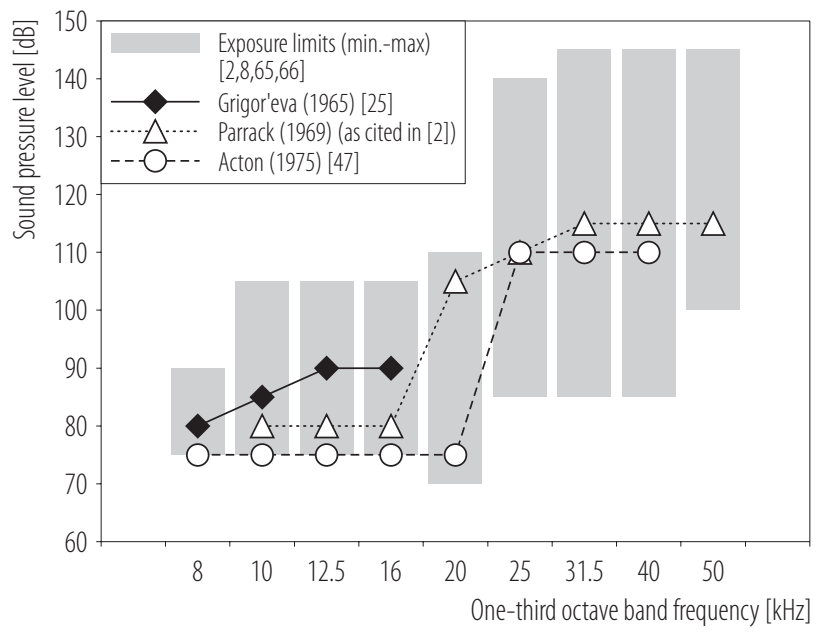

In addition to the permissible levels given in the graph, Grigor'eva [25] proposed a limit of $120 \mathrm{~dB}$ for the wide-band $(\geq 20 \mathrm{kHz}$ ) sound pressure level.

Figure 3. Exposure limits for very high-frequency sound and low-frequency airborne ultrasound applied in different countries, together with permissible levels recommended by individual researchers $[2,8,25,47,65,66]$

Roshchin and Dobroserdov [64] showed that SPLs of 90$110 \mathrm{~dB}$ in the range of lower frequencies $(21 \mathrm{kHz})$, and $110-115 \mathrm{~dB}$ in the range of higher frequencies $(40 \mathrm{kHz})$, constituted the limit of occurrence of functional changes.

\section{Occupational exposure limits}

A number of damage risk criteria and maximum permissible levels of occupational exposure limits for ultrasonic noise were prepared by individual researchers at the turn of the 1960s and 1970s. They were based on 2 fundamental assumptions. Firstly, high-frequency audible components $(10-20 \mathrm{kHz})$ are capable of causing annoyance, tinnitus, headaches, fatigue and nausea. Secondly, the high-level ultrasonic component (>20 kHz) may cause hearing impairment. Thus, the limit values were set at such a level which would avoid any subjective or auditory effects in any exposed individuals [38,65].

These tentative recommendations, supported by limited experimental data, were taken up by some national and international bodies, and a number of them are still in use. However, no regulations on low-frequency airborne ultrasound have so far been established in the European Union. Examples of the maximum permissible levels for very high-frequency sound and low-frequency ultrasound are presented in Table 1 and Figure 3.

\section{CONCLUSIONS}

Although research into the potential harmful effects of ultrasound and very high-frequency sound has been conducted for over half a century, relatively fewer papers on the ultrasound impact, as compared to the audible noise impact, have been published so far. Furthermore, many of the studies reviewed in this paper came from the 1960s-1970s. In turn, these investigations usually comprised a small number of subjects (over a dozen at a maximum). Furthermore, they often had some methodological and/or technical limitations, and were rather seldom supported by sufficient statistical analyses.

Generally, studies of the impact of low-frequency airborne ultrasound on the state of the hearing organ were difficult because in industrial conditions they are usually accompanied by audible noise. It is, therefore, difficult to determine whether the hearing changes of the subjects occur due to the influence of only high-frequency audible or only ultrasonic components, or as a result of a simultaneous action of both these factors.

According to the literature data, including especially the results of early studies, low-frequency airborne ultrasound has been recognized to cause auditory as well as non-auditory effects, in particular subjective symptoms, including fatigue, nausea, headaches, vomiting, pain, disturbed coordination, dizziness, etc. Other non-auditory effects such as thermal effects are rather unlikely to occur at SPLs normally occurring in the occupational and nonoccupational settings [9-12], since they are supposed to appear at the SPL of $>140-50 \mathrm{~dB}$.

Already in the 1960-1970s, it was shown that ultrasound was able to cause hearing effects, including TTS [2,16,21,26]. 
It was believed that any hazards of ultrasound to hearing were due to the audible components of high-frequency subharmonics which accompany ultrasound itself $[21,47,49]$. In 1982, the WHO stated that neither temporary nor permanent hearing loss should occur after exposure to ultrasound at SPLs of $<120 \mathrm{~dB}$ [2]. It was also suggested that TTS might occur after short-term exposures to lowfrequency ultrasound at $150 \mathrm{~dB}[16]$.

For years, Grzesik and Pluta [27-29] were 2 of the few researchers who demonstrated higher (worse) HTLs in the frequency range of $10-20 \mathrm{kHz}$ among operators of ultrasonic devices (as compared to matched controls), and estimated the progress of extended high-frequency hearing loss to be $1 \mathrm{~dB} /$ year. Nearly 30 years later, some new studies also showed worse results of the extended high-frequency audiometry among subjects working with ultrasonic devices, as compared to non-noise-exposed subjects or workers exposed to audible noise at a similar dBA level (but without ultrasonic components), while no significant differences were observed in the standard pure tone audiometry. However, it is still unclear whether such a situation is due to high-frequency audible sound or lowfrequency ultrasound, since extended high-frequency audiometry is generally more effective than PTA in detecting the early signs of hearing loss of various origins, including age-related and noise-induced hearing loss [17,18].

In turn, according to early studies, exposure to low-frequency airborne ultrasound, when sufficiently intense, also appears to result in a syndrome involving manifestations of nausea, headache, tinnitus, pain, dizziness, and fatigue. The type of the symptom and the degree of severity appear to vary, depending on the actual spectrum of ultrasonic exposure and the individual susceptibility of the exposed persons, particularly their hearing acuity at high frequencies (ultrasonic frequency) [21]. However, these studies did not include any statistical measures concerning the prevalence of various symptoms. Thus, it was not surprising that in the later investigations, though not too many, some subjective symptoms were usually experienced by only a part of the personnel working with ultrasonic devices [30,32]. Furthermore, no sufficient evidence has been provided to date that the ultrasound emitted by the devices in public places provokes subjective symptoms such as nausea, pain, pressure or fullness in the ears, headaches, dizziness, anxiety and fatigue [54-57]. However, some insignificant placebo effects have been presented [57].

An important issue seems to be the auditory perception of low-frequency airborne ultrasound. It has been known that some people can perceive sound at frequencies of $>16-20 \mathrm{kHz}$. However, at present, the mechanisms of hearing perception at these frequencies are not well understood [42]. In turn, this lack of knowledge is reflected in the existing regulations. The few existing governmental guidelines for ultrasonic exposure mainly refer to the same very limited literature data $[8,38,65]$.

To sum up, generally rather little work has been done since the 1960s-1970s. Thus, further studies are needed before any firm conclusions can be drawn about the auditory and non-auditory effects of low-frequency airborne ultrasound in the occupational environment, especially because the devices emitting "pure" ultrasound are being increasingly used not only in the general environment, but also in the working environment.

\section{REFERENCES}

1. Duck F, Leighton TG. Frequency bands for ultrasound, suitable for the consideration of its health effects. J Acoust Soc Am. 2018;144:2490, https://doi.org/10.1121/1.5063578.

2. Environmental Health Criteria 22, Ultrasound, Published under the joint sponsorship of the United Nations Environment Programme, the World Health Organization, and the International Radiation Protection Association. Geneva: World Health Organization 1982.

3. Ahmadi F, McLoughlin IF, Chauhan S, ter-Haar G. Bioeffects and safety of low-intensity, low-frequency ultrasonic exposure. Prog Biophys Mol Biol. 2012;108(3):119-38, https://doi.org/10.1016/j.pbiomolbio.2012.01.004. 
4. Izadifar Z, Babyn P, Chapman D. Mechanical and biological effects of ultrasound: a review of present knowledge. Ultrasound Med Biol. 2017;43(6):1085-104, https://doi. org/10.1016/j.ultrasmedbio.2017.01.023.

5. Health Canada. Guidelines for the Safe Use of Ultrasound: Part II - Industrial and Commercial Applications. Safety code 24. Catalogue No. H46-2/90-158E [Internet]. Ottawa: Ministry of Supply and Services Canada; 1991 [cited 2019 Dec 13]. Available from: https://www.canada.ca/en/healthcanada/services/environmental-workplace-health/reportspublications/radiation/guidelines-safe-use-ultrasound-partindustrial-commercial-applications-safety-code-24.html.

6. Leighton TG. Are some people suffering as a result of increasing mass exposure of the public to ultrasound in air? Proc Math Phys Eng Sci. 2016;472(2185):20150624, https:// doi.org/10.1098/rspa.2015.0624.

7. Fletcher MD, Lloyd Jones S, White PR, Dolder CN, Lineton B, Leighton TG. Public exposure to ultrasound and very high-frequency sound in air. J Acoust Soc Am. 2018;144(4):2554, https://doi.org/10.1121/1.5063817.

8. Pawlaczyk-Łuszczyńska M, Koton J, Śliwińska-Kowalska M, Augustyńska D, Kameduła M. [Verified maximum admissible intensity (MAI) values for the ultrasonic noise in work environment]. Med Pr. 2001;52(3):221-6. Polish.

9. Pawlaczyk-Łuszczyńska M, Dudarewicz A, Śliwińska-Kowalska M. [Sources of occupational exposure to ultrasonic noiseevaluation of selected devices]. Med Pr. 2007;58(2):105-16. Polish.

10. Smagowska B. Ultrasonic noise sources in a work environment. Arch Acoust. 2013;38(2):169-76, https://doi.org/10.2478/ aoa-2013-0019.

11. Smagowska B. An objective and subjective study of noise exposure within the frequency range from $10 \mathrm{kHz}$ to $40 \mathrm{kHz}$. Arch Acoust. 2013;38(4):559-63, https://doi.org/10.2478/aoa-2013-0066.

12. Szłapa P, Marczak W. Arc welding noise assessment from the measured ultrasound pressure levels. Part I: The metal active gas welding. Ultrasonics. 2020;100:105976, https://doi. org/10.1016/j.ultras.2019.105976.
13. Davis H. Biological and psychological effects of ultrasonics. J Acoust Soc Am. 1948;20(5):605-7, https://doi.org/10.1121/ 1.1906414.

14. Allen CH, Frings H, Rudnik I. Some biological effects of intense high frequency airborne sound. J Acoust Soc Am. 1948;20(1):62-5, https://doi.org/10.1121/1.1906349.

15. Acton WI, Carson MB. Auditory and subjective effects of airborne noise from industrial ultrasonic sources. Br J Ind Med. 1967;24(4):297-304, https://doi.org/10.1136/oem.24.4.297.

16. Parrack HO. Ultrasound and industrial medicine. Ind Med Surg. 1952;21(4):156-64.

17. Ahmed HO, Dennis JH, Badran O, Isamil M, Ballal SG, Ashoor A, et al. High frequency $(10-18 \mathrm{kHz})$ hearing thresholds: reliability, and effects of age and occupational noise exposure. Occup Med. 2001;51(4):245-58, https://doi. org/10.1093/occmed/51.4.245.

18. Somma G, Pietroiusti A, Magrini A, Coppetta L, Ancona C, Gardi S, et al. Extended high frequency audiometry and noise induced hearing loss in cement workers. Am J Ind Med. 2008;51(6):452-62, https://doi.org/10.1002/ajim.20580.

19. Dallos PJ, Linnel CO. Subharmonic components in cochlear-microphonic potentials. J Acoust Soc Am. 1966;40(1):411, https://doi.org/10.1121/1.1910063.

20. Dallos PJ, Linnel CO. Even-order subharmonics in the peripheral auditory system. J Acoust Soc Am. 1966;40:561, https://doi.org/10.1121/1.1910119.

21. Acton WI. The effects of industrial airborne ultrasound on humans. Ultrasonics. 1974;12(3):124-8, https://doi.org/10. 1016/0041-624X(74)90069-9.

22. Acton WI. A criterion for the prediction of auditory and subjective effects due to airborne noise from ultrasonic sources. Ann Occup Hyg. 1968;11(3):227-34, https://doi.org/10.1093/ annhyg/11.3.227.

23. Knight JJ. Effects of airborne ultrasound on man. Ultrasonics. 1968;6(1):39-41, https://doi.org/10.1016/0041-624x(68)90 016-4.

24. Milkov LE, Grigor'eva VM, Stepanova VI, Ponomareva NI, Chulina NA, Saittanov AO. [Problems of industrial hygiene 
and occupational diseases in the operation of ultrasonic equipment]. Gig Tr Prof Zabol. 1968;6(12):8-14. Russian.

25. Grigor'eva VM. [Effects of ultrasonic vibrations on personnel working with of the ultrasonic equipment]. Akust Zhurnal. 1965;11(4):469-97. Russian.

26. Dobroserdov VK. [On the effect of low frequency ultrasonic waves and high frequency sound waves on the organism of workers]. Gig Sanit. 1967;32:17-21. Russian.

27. Grzesik J, Pluta E. High-frequency hearing risk of operators of industrial ultrasonic devices. Int Arch Occup Environ Heath. 1983;53(1):77-88, https://doi.org/10.1007/bf00406179.

28. Grzesik J, Pluta E. High-frequency noise-induced hearing loss: a field study on the role of intensity level and accumulated noise dose. Int Arch Occup Environ Health. 1986;57(2): 127-36, https://doi.org/10.1007/BF00381380.

29. Grzesik J, Pluta E. Dynamics of high frequency hearing loss of operators of industrial ultrasonic devices. Int Arch Occup Environ Health. 1986;57(2):137-42, https://doi.org/10.1007/ bf00381381.

30. Macca I, Scapellato ML, Carrieri M, Maso S, Trevisan A, Bartolucci GB. High-frequency hearing thresholds: effects of age, occupational ultrasound and noise exposure. Int Arch Occup Environ Health. 2015;88(2):197-211, https:// doi.org/10.1007/s00420-014-0951-8.

31. Dudarewicz A, Zaborowski K, Rutkowska-Kaczmarek P, Zamojska-Daniszewska M, Śliwińska-Kowalska M, Zamysłowska-Szmytke E, et al. The hearing threshold of employees exposed to noise generated by the low-frequency ultrasonic welding devices. Arch Acoust. 2017;42(2):199-205, https:// doi.org/10.1515/aoa-2017-0022.

32. Pawlaczyk-Łuszczyńska M, Dudarewicz A, Śliwińska-Kowalska $\mathrm{M}$. Theoretical predictions and actual hearing threshold levels in workers exposed to ultrasonic noise of impulsive character - a pilot study. Int J Occup Saf Ergon. 2007;13(4):409-18, https://doi.org/10.1080/10803548.2007.11 105098.

33. Chopra A, Thomas BS, Mohan K, Sivaraman K. Auditory and nonauditory effects of ultrasonic scaler use and its role in the development of permanent hearing loss. Oral Health Prev Dent. 2016;14(6):493-500, https://doi.org/10.3290/j.ohpd. a36520.

34. Möller P, Grevstad AO, Kristoffersen T. Ultrasonic scaling of maxillary teeth causing tinnitus and temporary hearing shifts. J Clin Periodontol. 1976;3(2):123-7, https://doi. org/10.1111/j.1600-051x.1976.tb01858.x.

35. Rahko AA, Karma PH, Rahko KT, Kataja MJ. High-frequency hearing of dental personnel. Commun Dent Oral Epidemiol. 1988;16:268-70, https://doi.org/10.1111/j.1600-0528.1988. tb01771.x.

36. Wilson JD, Darby ML, Tolle SL, Sever JC Jr. Effects of occupational ultrasonic noise exposure on hearing of dental hygienists: a pilot study. J Dent Hyg. 2002;76(4):262-9.

37. Rodríguez Valiente A, Trinidad A, García Berrocal JR, Górriz C, Ramírez Camacho R. Extended high-frequency (9-20 kHz) audiometry reference thresholds in 645 healthy subjects. Int J Audiol. 2014;53(8):31-45, https://doi.org/10. 3109/14992027.2014.893375.

38. Lawton BW. Damage to human hearing by airborne sound of very high frequency or ultrasonic frequency. Contract Research Report No 343/2001 [Internet]. Institute of Sound and Vibration Research for the Health and Safety Executive; 2001 [cited 2019 Dec 13]. Available from: http://www. hse.gov.uk/research/crr_pdf/2001/crr01343.pdf.

39. Henry KR, Fast GA. Ultrahigh-frequency auditory thresholds in young adults: reliable responses up to $24 \mathrm{kHz}$ with a quasi-free-field technique. Audiology. 1984;23(5):477-89, https://doi.org/10.3109/00206098409070087.

40. Ashihara K, Kurakata K, Mizunami T, Matsushita K. Hearing threshold for pure tones above $20 \mathrm{kHz}$. Acoust Sci Technol. 2006;27(1):12-9, https://doi.org/10.1250/ast.27.12.

41. Ashihara K. Hearing threshold for pure tones above 16 kHz. J Acoust Soc Am. 2007;122(3):12-9, https://doi.org/ 10.1121/1.2761883.

42. Koch C. Hearing beyond the limit: Measurement, perception and impact of infrasound and ultrasonic noise. In: Proceedings of the 12th ICBEN Congress on Noise as a Public 
Health Problem; 2017 Jun 18-22, Zurich, Switzerland (ID:4163) [Internet] [cited 2019 Dec 13]. Available from: http://www.icben.org/2017/ICBEN\%202017\%20Papers/ Keynote02_Koch_4163.pdf.

43. Fujioka T, Kakigi R, Gunji A, Takeshima Y. The auditory evoked magnetic fields to very high frequency tones. Neuroscience. 2002;112(2):367-81, https://doi.org/10.1016/s03064522(02)00086-6.

44. Hosoi H, Imaizumi S, Sakaguchi T, Tonoike M, Murata K. Activation of the auditory cortex by ultrasound. Lancet. 1998;351(9101):496-7, https://doi.org/10.1016/S0140-6736(05) 78683-9.

45. Oohashi T, Nishina E, Honda M, Yonekura Y, Fuwamoto Y, Kawai N, et al. Inaudible high-frequency sounds affect brain activity: hypersonic effect. J Neurophysiol. 2000;83(6):354858, https://doi.org/10.1152/jn.2000.83.6.3548.

46. Kühler R, Weichenberger M, Bauer M, Hensel J, Brühl R, Ihlenfeld A, et al. Does airborne ultrasound lead to activation of the auditory cortex? Biomed Eng-Biomed Tech. 2019;64(4):481-93, https://doi.org/10.1515/bmt-2018-0048.

47. Acton WI. Exposure criteria for industrial ultrasound. Ann Occup Hyg. 1975;18(3):267-8, https://doi.org/10.1093/ annhyg/18.3.267.

48. Crabtree RB, Forshaw SE. Exposure to ultrasonic cleaner noise in the Canadian Forces. DCIEM Technical Report no. 77X45 (July 1977). [Internet]. Ontario: Behavioural Division, Defense and Civil Institute of Environmental Medicine, Downs view; 1977 [cited 2019 Dec 13]. Available from: https://docplayer.net/78329146-Exposure-to-ultrasoniccleaner-noise.html.

49. Acton WI. Exposure to industrial ultrasound: hazards, appraisal and control. J Soc Occup Med. 1983;33(3):107-13, https://doi.org/10.1093/occmed/33.3.107.

50. Skillern CP. Human response to measured sound pressure levels from ultrasonic devices. Am Ind Hyg Assoc J. 1965;26(2): 132-6, https://doi.org/10.1080/00028896509342712.

51. Herman BA, Powell D. Airborne ultrasound: Measurement and possible adverse effects. HHS Publication (FDA)
81-8163. Rockville: US Department of Health and Human Services, Food and Drug Administration; 1981.

52. Smith SD, Nixon CW, von Gierke HE. Damage risk criteria for hearing and human body vibration. In: Vér IL, Beranek LL, editors. Noise and vibration control engineering: principles and applications. New York, NY: Wiley; 1992. p. 598-600.

53. Holmberg K, Landström U, Nordström B. Annoyance and discomfort during exposure to high-frequency noise from an ultrasonic washer. Percept Mot Skills. 1995;81(3):819-27, https://doi.org/10.2466/pms.1995.81.3.819.

54. Ueda M, Ota A, Takahashi H. Investigation on high-frequency noise in public space. In: Proceedings of the Inter-Noise 2014, 43rd International Congress on Noise Control Engineering; 2014 Nov 16-19; Melbourne, Australia [Internet] [cited 2019 Dec 13]. Available from: http://www.acoustics.asn.au/conference_proceedings/INTERNOISE2014/papers/p384.pdf.

55. Van Wieringen A, Glorieux C. Assessment of short-term exposure to an ultrasonic rodent repellent device. J Acoust Soc Am. 2018;144:2501, https://doi.org/10.1121/1.5063987.

56. Fletcher MD, Jones SL, White PR, Dolder CN, Leighton TG, Lineton B. Effects of very high-frequency sound and ultrasound on humans. Part I: Adverse symptoms after exposure to audible very-high frequency sound. J Acoust Soc Am. 2018;144:2511, https://doi.org/10.1121/1.5063819.

57. Fletcher MD, Jones SL, White PR, Dolder CN, Leighton TG, Lineton B. Effects of very high-frequency sound and ultrasound on humans. Part II: A double-blind randomized provocation study of inaudible 20-kHz ultrasound. J Acoust Soc Am. 2018;144:2521; https://doi.org/10.1121/1.5063818.

58. Neppiras EA. Acoustic cavitation thresholds and cyclic processes. Ultrasonics. 1980;18:201-9, https://doi.org/10.1016/00 41-624X(80)90120-1.

59. Danner PA, Ackerman E, Frings HW. Heating in haired and hairless mice in high intensity sound fields from $6-22 \mathrm{kHz}$. J Acoust Soc Am. 1954;26(1):141-2.

60. Markiewicz L. [Results of the study on the ultrasonic vibrations impact on human body]. Mater Stud Bad CIOP. 1978;43:41-9. Polish. 
61. Grzesik J, Pluta E. [The assessment criteria and examination of health status of people operating ultrasonic devices]. Mater Stud Bad CIOP. 1978;43:30-40. Polish.

62. Schust M. [Biological effects of airborne ultrasound (technical report)]. Bremerhaven: Federal Institute for Occupational Safety and Health; 1996. German.

63. Il'nitskaia AV, Pal'tsev IuP. [Combined action of ultrasonics and noise of standard parameters]. Gig Sanit. 1973;5:50-3. Russian.

64. Roshchin AV, Dobroserdov VK. [Reactions of the human auditory analysor to the effect of high frequency acoustic oscillations]. Gig Tr Prof Zabol. 1971;15(12):3-7. Russian.
65. Lawton BW. Exposure limits for airborne sound of very high frequency and ultrasonic frequency. ISVR Technical Report No: 334. [Internet]. Southampton: University of Southampton; 2013 [cited 2019 Dec 13]. Available from: https:// eprints.soton.ac.uk/351902/.

66. [The Decree issued by the Minister of Family, Labour and Social Policy of June 23, 2018 on maximum admissible concentration and maximum admissible intensity values for agents harmful to human health in the work environment. J Laws 2018 No. 0, item 1286, as amended]. Polish.

This work is available in Open Access model and licensed under a Creative Commons Attribution-NonCommercial 3.0 Poland License - http://creativecommons.org/ licenses/by-nc/3.0/pl/deed.en. 